Article

\title{
Study on the Flame Retardancy and Hazard Evaluation of Poly(acrylonitrile-co-vinylidene chloride) Fibers by the Addition of Antimony-Based Flame Retardants
}

\author{
Hyelim Kim ${ }^{1}{ }^{\circledR}$, Ji-Su Kim ${ }^{2}$ and Wonyoung Jeong ${ }^{1, * \mathbb{C}}$ \\ 1 Material and Component Convergence R\&D Department, KITECH, Ansan 15588, Korea; \\ hyelim1221@kitech.re.kr \\ 2 Advanced Testing \& Evaluation Center, FITI Testing \& Research Institute, Seoul 07791, Korea; \\ jisu123@fitiglobal.com \\ * Correspondence: wyjeong@kitech.re.kr
}

check for

updates

Citation: Kim, H.; Kim, J.-S.; Jeong, W. Study on the Flame Retardancy and Hazard Evaluation of Poly(acrylonitrile-co-vinylidene chloride) Fibers by the Addition of Antimony-Based Flame Retardants. Polymers 2022, 14, 42. https:// doi.org/10.3390/polym14010042

Academic Editors: Jun Sun,

Yongqian Shi and Zhi Li

Received: 19 November 2021

Accepted: 21 December 2021

Published: 23 December 2021

Publisher's Note: MDPI stays neutral with regard to jurisdictional claims in published maps and institutional affiliations.

Copyright: (c) 2021 by the authors. Licensee MDPI, Basel, Switzerland. This article is an open access article distributed under the terms and conditions of the Creative Commons Attribution (CC BY) license (https:// creativecommons.org/licenses/by/ $4.0 /)$.

\begin{abstract}
Antimony oxide (ATO) is used mainly as a flame retardant, but it is classified as a hazardous substance. Therefore, regulations on the use of antimony trioxide $(\operatorname{ATO}(3))$ and antimony pentoxide $(\mathrm{ATO}(5))$ in textile products are being developed. Accordingly, there is a need for alternative flame retardants. In this study, antimony tetroxide $(\mathrm{ATO}(4))$, which has higher thermal stability and resistance to acids and alkalis than $\mathrm{ATO}(3)$ or $\mathrm{ATO}(5)$, was selected to assess its use as an alternative flame retardant. First, ATO(3) or ATO(4) were added to poly(acrylonitrile-co-vinylidene chloride) (PANVDC), and the film and wet-spun fiber were prepared. The PANVDC film with flame retardants was prepared to evaluate the flame retardancy and the mechanism of action of the flame retardants. Flame retardancy analysis showed that a limiting oxygen index of $31.2 \%$ was obtained when ATO(4) was added, which was higher than when ATO(3) was used. Subsequently, PANVDC fibers with antimony oxide were manufactured and showed improved mechanical and thermal properties when $\mathrm{ATO}(4)$ was used, compared to when $\mathrm{ATO}(3)$ was tested. In addition, migration analysis due to antimony in the fiber confirmed that the elution amount was below the acceptable standard when PANVDC fibers with ATO(4) were added. Therefore, based on these results, the flame-retardant and thermal properties of antimony tetroxide were superior to antimony trioxide, and it was confirmed that $\mathrm{ATO}(4)$ could be used as an alternative flame retardant to $\mathrm{ATO}(3)$.
\end{abstract}

Keywords: flame retardancy; poly(acrylonitrile-co-vinylidene chloride); antimony trioxide; antimony tetroxide; hazard evaluation

\section{Introduction}

As fire-related accidents increase in industry worldwide, the demand for flameretardant (FR) materials and work clothes related directly to safety is continuously increasing every year. Accordingly, the demand for FR fabrics that are comfortable to wear and lightweight is increasing. Currently, modacrylic fibers, which have excellent flame retardancy, price competitiveness, and an excellent tactile feel, are attracting attention as a FR workwear fiber material. Modacrylic fibers are defined as those fibers containing 35-85 wt.\% acrylonitrile (AN) units. Poly(acrylonitrile-co-vinylidene chloride) (PANVDC) fibers are copolymers synthesized for modacrylic fibers [1-3]. Generally, poly(acrylonitrile) (PAN) has a limiting oxygen index (LOI) in the range of $18-20 \%$, while modacrylic fibers have excellent flame retardant properties in the range of 26-31\% LOI [4-6]. On the other hand, various flame retardant additives are used to maximize the LOI because a higher level of flame retardancy is required in extreme environments at high temperatures [7-9].

Antimony oxide is one of the most representative flame retardants. Antimony trioxide $\left(\mathrm{ATO}, \mathrm{Sb}_{2} \mathrm{O}_{3}\right)$ is commonly used with halogenated flame retardants to yield a promotional effect. The material does not have excellent flame retardancy itself, but when applied to halogen-based compounds, such as poly(vinyl chloride) (PVC), it works in 
the gas phase by facilitating the migration of halogens and antimony into the gas phase for flame retardation/inhibition $[3,7,8,10,11]$. Accordingly, the incorporation of ATO in poly(acrylonitrile-co-vinyl chloride) (PANVC) or poly(acrylonitrile-co-vinylidene chloride) (PANVDC) fibers has synergistic effects on their flame retardancy. On the other hand, antimony trioxide was recently classified as a carcinogen in Europe, and its use was regulated $[12,13]$. Therefore, various studies were conducted to reduce the antimony oxide used for halogen compounds and use a human-friendly flame retardant additive that could replace it $[9,14]$. In a previous study, a flame retardancy was confirmed by adding a different type of flame retardant to replace antimony trioxide, and, as a result, it was reported that flame retardancy was indicated even when a small amount of antimony trioxide was mixed or entirely replaced [15-18]. On the other hand, research on new flame-retardant additives is needed because it is difficult to sufficiently reduce the use of antimony trioxide.

Antimony tetroxide $\left(\mathrm{Sb}_{2} \mathrm{O}_{4}\right)$ contains a mixed valance of $\mathrm{Sb}_{2} \mathrm{O}_{3}$ and $\mathrm{Sb}_{2} \mathrm{O}_{5}$ [11]. Although antimony tetraoxide ( $\mathrm{Sb} 2 \mathrm{O} 4)$ is an antimony-based compound, as is antimony trioxide $\left(\mathrm{Sb}_{2} \mathrm{O}_{3}\right)$, there are few reports on its toxicity, flame retardancy or antimony elution when applied to textiles. Therefore, research in this area is required. In the present study, antimony tetroxide was selected as an alternative flame retardant additive to antimony trioxide, which is generally used in modacrylic fibers. Each additive was added to poly(acrylonitrile-co-vinylidene chloride) to prepare the fibers through a wet-spinning process. To investigate their physical properties, the thermal and flame retardancy of the prepared spun fibers were evaluated, and the antimony elution in acidic and alkaline solutions was analyzed.

\section{Experimental Section}

\subsection{Materials}

The poly (acrylonitrile-co-vinylidene chloride) (PANVDC) copolymer was used in this study. The PANVDC is a commercial flame-retardant modacrylic material with a composition of acrylonitrile (AN, Across, $\geq 99 \%$ ) and vinylidene chloride (VDC, Across, $\geq 98.0 \%$ ) and a molar ratio of 7:3. The number average molecular weight and polydispersity of PANVDC were $62,000 \mathrm{~g} / \mathrm{mol}$ and 2.56 , respectively. Figure 1 shows the two flame retardant additives used in this study, Antimony trioxide $\left(\mathrm{Sb}_{2} \mathrm{O}_{3}, \mathrm{ATO}(3)\right)$ and antimony tetroxide $\left(\mathrm{Sb}_{2} \mathrm{O}_{4}, \mathrm{ATO}(4)\right)$, which were purchased from Sooyangchemtec Co. Ltd., (Yesan, Korea). Dimethyl sulfoxide (DMSO, 99.9\%, Samchun Chemical Co., Ltd., Seoul, Korea) was used as the solvent without further purification.

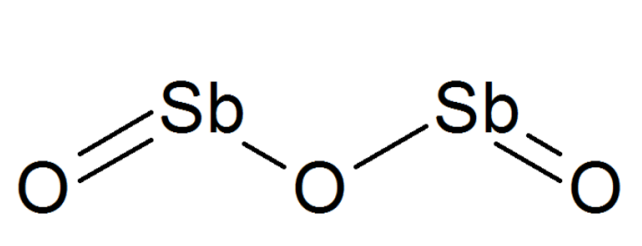

(a)

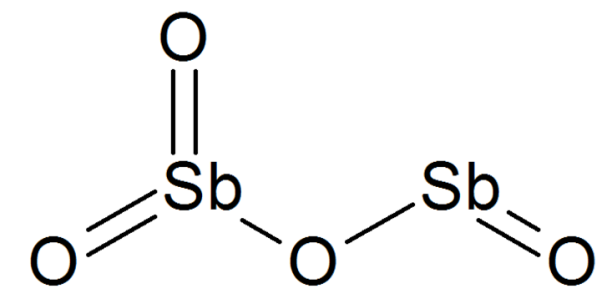

(b)

Figure 1. Molecular structure of the antimony oxides (a) Antimony trioxide (ATO(3)), (b) Antimony tetroxide $(\mathrm{ATO}(4))$.

\subsection{Wet Spinning of PANVDC Flame-Retardant Fibers}

Figure 2 represents the scheme of wet-spinning system. The PANVDC fibers, along with the types of flame retardants, were prepared using a laboratory-scale wet-spinning system [16]. DMSO was used as the solvent because it is relatively less toxic than other solvents. To prepare the spinning solution, $35 \mathrm{wt} . \%$ of PANVDC was dissolved in DMSO. The flame retardant, either $\mathrm{Sb}_{2} \mathrm{O}_{3}(\mathrm{ATO}(3))$ or $\mathrm{Sb}_{2} \mathrm{O}_{4}(\mathrm{ATO}(4))$, was dispersed using an ultrasonic bath (Power sonic 420, Whashin Tech Co., Gyeonggi, South Korea) for $20 \mathrm{~min}$. For the wet-spinning process, the prepared spinning solution was stored at $50{ }^{\circ} \mathrm{C}$, and 
filtered through a 400 mesh, and spun into a DMSO $/ \mathrm{H}_{2} \mathrm{O}$ coagulation bath $(70 / 30 w / w)$ using a 100-filament spinneret with $70 \mu \mathrm{m}$ capillary diameters at a speed of $1.22 \mathrm{~mL} / \mathrm{min}$. Distilled water was used for the washing bath and heat drawing bath. Subsequently, the residual solvent was prepared by drawing and drying processes. The fibers were finally dried in a $60{ }^{\circ} \mathrm{C}$ convection oven for $24 \mathrm{~h}$.

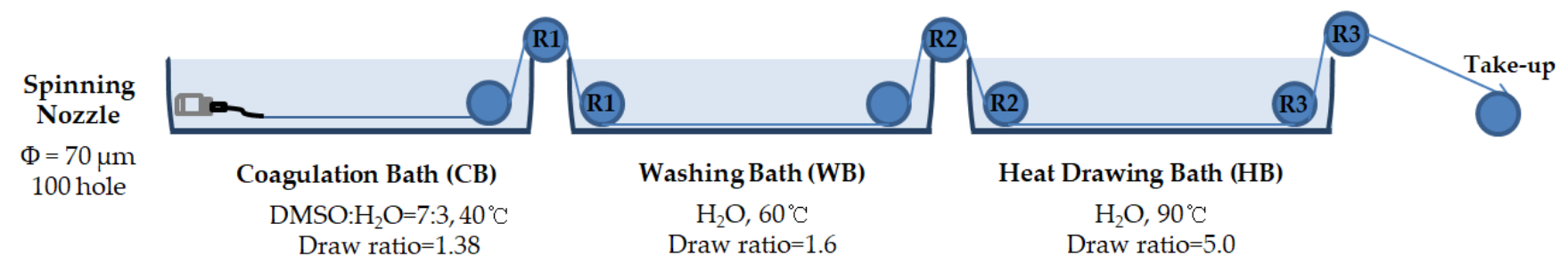

Figure 2. Wet-spinning system used in this study.

\subsection{Characterization}

- Flame-Retardant Mechanisms

Pyrolysis-gas chromatography-mass spectrometry (Py-GC/MS) was investigated using the sampling procedure reported elsewhere [16]. Py-GC/MS was conducted on a pyroprobe (PY-2020iD, Frontier, Fukushima, Japan) combined with a gas chromatograph (7890, Agilent, Santa Clara, CA, USA) and mass spectrometer (5975, Agilent, Santa, Clara, CA, USA). The pyrolysis temperature ranged from room temperature to $600{ }^{\circ} \mathrm{C}$ in a nitrogen atmosphere at a heating rate of $20^{\circ} \mathrm{C} / \mathrm{min}$. The volatile products were then sent to the GC injector with a set temperature of $320^{\circ} \mathrm{C}$. The char layer of the PANVDC fibers was examined by scanning electron microscopy combined with energy-dispersive $\mathrm{X}$-ray spectroscopy (SEM-EDX, SU8000, Hitachi, Tokyo, Japan).

\section{- Flame Retardancy of PANVDC Film}

Flame retardancy was investigated by performing two tests reported elsewhere $[16,17]$. All samples were prepared in the form of a film. First, the vertical burning tests were conducted according to the UL 94 (UnderWriter's Laboratory, Vertical Burning Test) under controlled laboratory conditions. The test was performed twice with $20 \mathrm{~mm}$ vertical flame contacting a $125 \mathrm{~mm} \times 13 \mathrm{~mm}$ molded sample for $10 \mathrm{~s}$. To pass UL $94 \mathrm{~V} 2$, the flame should extinguish within $30 \mathrm{~s}$ after each ignition. Burning drips are allowed. For UL $94 \mathrm{V0}$, the flame should extinguish within $10 \mathrm{~s}$ after each ignition, with less than $50 \mathrm{~s}$ for the total burning of five samples and no burning drips. Another method used to analyze the flame retardancy in this study was the LOI, which is the standard of ISO 4589-2. At this time, the size of the specimen was $100 \mathrm{~mm} \times 10 \mathrm{~mm} \times 0.05 \mathrm{~mm}$.

\section{- Morphology and Mechanical properties of PANVDC Fiber}

The morphology of the PANVDC fibers containing the flame retardant was investigated by analyzing a cross-section of a prepared fiber by field emission scanning electron microscopy (FE-SEM, Hitachi SU8000, Hitachi High-Technologies Corporation, Tokyo, Japan). To confirm the mechanical properties of each sample, the tensile properties of single fibers were tested using the Favimat fiber test system (Favimat fiber test system2, Textehchno H., Mönchengladbach, Germany). The test was conducted at least 10 times at a crosshead speed of $20 \mathrm{~mm} / \mathrm{min}$ and a gauge length of $20 \mathrm{~mm}$.

\section{- Thermal Properties of PANVDC Fiber}

Thermogravimetric analysis (TGA, TA Instruments Q 500, New Castle, DE, USA) was performed under flowing air at a heating rate of $20^{\circ} \mathrm{C} / \mathrm{min}$ from room temperature to $800^{\circ} \mathrm{C}$.

- Migration of antimony in the PANVDC fibers 
According to the standard of KS G ISO 8124-3 and KS K 0731, antimony elution was evaluated in acidic and alkaline solutions, such as sweat and saliva. Figure 3 shows the process of migration of antimony. First, impregnating a $100 \mathrm{mg}$ fiber specimen in the test solution. Using that solution, centrifugation was performed to separate the specimen and the eluate. After that, antimony contents in this solution were investigated through inductively coupled plasma-optical emission spectroscopy (ICP-OES, ULTIMA 2, HORIBA Scientific, Kyoto, Japan). The evaluation was performed after stabilizing the eluate concentration to $1 \mathrm{~mol} / \mathrm{L}$ for storage for more than one day.

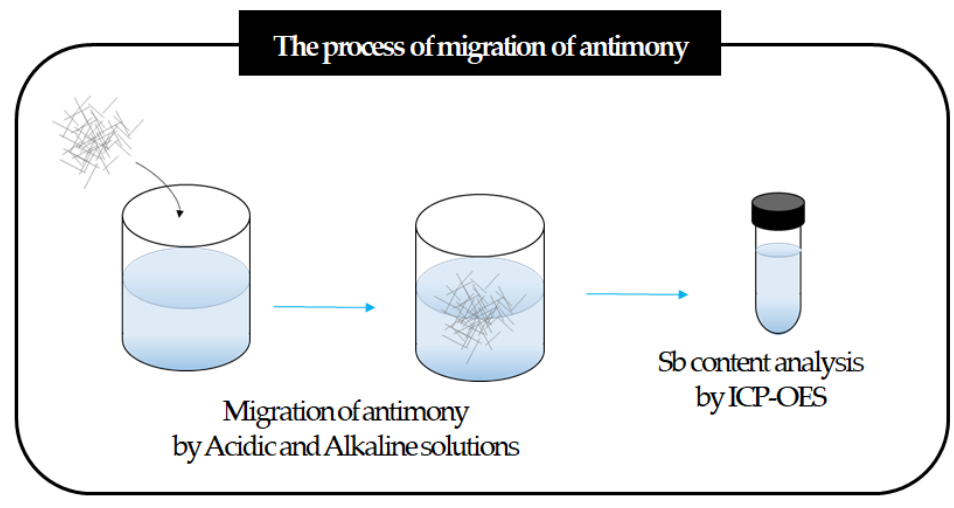

Figure 3. Process of migration of antimony.

The extractable antimony content in the sample was calculated using Equation (1):

$$
\left(C-C_{0}\right) / W \times V \times F
$$

where $C$ is the concentration of the object element in the test solution $(\mathrm{mg} / \mathrm{L}) ; C_{0}$ is the concentration of target element among background test solution $(\mathrm{mg} / \mathrm{L}) ; W$ is mass of the specimen $(\mathrm{g}) ; V$ is the volume of test solution used $(\mathrm{mL})$; and $F$ is the dilution rate.

\section{Results and Discussion}

\subsection{Flame Retardant Mechanism of PANVDC Films with Flame Retardants}

Table 1 lists the Py-GC/MS results of PANVDC fibers with either ATO(3) or ATO(4). Py-GC/MS of evolved gases of the PANVDC fibers at thermal decomposition at $600{ }^{\circ} \mathrm{C}$ was carried out. $\mathrm{Sb}_{2} \mathrm{O}_{4}$ is a compound of $\mathrm{Sb}_{2} \mathrm{O}_{3}$ and $\mathrm{Sb}_{2} \mathrm{O}_{5}$, containing a mixed valence of both materials. The density of $\mathrm{Sb}_{2} \mathrm{O}_{4}\left(307.52 \mathrm{~g} / \mathrm{mol}, 6.64 \mathrm{~g} / \mathrm{cm}^{3}\right)$ is higher than $\mathrm{Sb}_{2} \mathrm{O}_{3}$ $\left(291.52 \mathrm{~g} / \mathrm{mol}, 5.20 \mathrm{~g} / \mathrm{cm}^{3}\right)$ and $\mathrm{Sb}_{2} \mathrm{O}_{5}\left(323.52 \mathrm{~g} / \mathrm{mol}, 3.78 \mathrm{~g} / \mathrm{cm}^{3}\right)$, but its molecular weight is intermediate. In addition, the two stable modifications of $\mathrm{Sb}_{2} \mathrm{O}_{4}$ are the room temperature orthorhombic $\alpha$-phase (cervantite) and the high-temperature monoclinic $\beta$-phase [11].

As shown in Table 1, the major pyrolysis products of the PANVDC-based fibers included hydrogen chloride $(\mathrm{HCl})$. Here, $\mathrm{HCl}$ plays a vital role in the flame retardancy of halogen compounds and the synergistic effect of hydrogen chloride and antimony compounds in the flame-retardant mechanisms of halogen compounds [7]. Compared to PANVDC and PANVDC-ATO(3), the decomposition compounds were the same except for the antimony compounds. Pyridine, which is the decomposition compound of the chloropyridine isomer, found in both PANVDC and PANVDC-ATO (3), appears to be caused by the formation of stable carbonized structures in polyacrylonitrile (PAN) [16,19].

An antimony compound was detected as a volatile thermal decomposition product, confirming that both $\mathrm{ATO}(3)$ and $\mathrm{ATO}(4)$ had a flame retardant mechanism in the gas phases. On the other hand, in the case of PANVDC-ATO(4), cyanopentadiene, 3methylbenzonitrile, and 3-chlorobenzonitrile, including chloropyridine isomers, which are identified as the major peak in PANVDC and PANVDC-ATO(3), were not detected. When PANVDC contained ATO(4), it exhibited a flame retardancy in a reaction different from PANVDC-ATO(3). According to the properties of antimony oxides, ATO(4) does not 
exhibit a significant change in the carbon-nitrogen bond of the polycyclic structure after thermal decomposition at $600{ }^{\circ} \mathrm{C}$ when added to PANVDC fibers because ATO(4) has a stable structure and exhibits a heat resistance at high temperatures.

Table 1. Gas products through the pyrolysis of PANVDC fibers containing antimony oxide.

\begin{tabular}{|c|c|c|c|c|c|}
\hline \multicolumn{2}{|r|}{ PANVDC } & \multicolumn{2}{|c|}{ PANVDC-ATO(3) } & \multicolumn{2}{|c|}{ PANVDC-ATO(4) } \\
\hline $\begin{array}{c}\text { Retention } \\
\text { Time } \\
\text { (Min) }\end{array}$ & $\begin{array}{l}\text { Pyrolysis } \\
\text { Products }\end{array}$ & $\begin{array}{l}\text { Retention } \\
\text { Time } \\
\text { (Min) }\end{array}$ & $\begin{array}{l}\text { Pyrolysis } \\
\text { Products }\end{array}$ & $\begin{array}{c}\text { Retention } \\
\text { Time } \\
\text { (Min) }\end{array}$ & $\begin{array}{l}\text { Pyrolysis } \\
\text { Products }\end{array}$ \\
\hline 1.469 & hydrogen chloride * & 1.469 & hydrogen chloride * & 1.770 & hydrogen chloride ${ }^{*}$ \\
\hline 1.679 & Acrylonitrile * & 1.679 & Acrylonitrile * & 2.017 & Acrylonitrile * \\
\hline 1.908 & Methylacrylonitrile* & 1.908 & Methylacrylonitrile * & 2.264 & Methylacrylonitrile * \\
\hline 2.923 & 2,4-pentadienenitrile & 2.923 & 2,4-pentadienenitrile & 3.380 & 2,4-pentadienenitrile \\
\hline 4.313 & cyanopentadiene & 4.313 & cyanopentadiene & - & 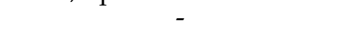 \\
\hline $5.319 \sim 5.466$ & chloropyridine isomers * & $5.319 \sim 5.466$ & chloropyridine isomers * & - & - \\
\hline 5.694 & 2-pentenedinitrile & 5.694 & 2-pentenedinitrile & 6.225 & 2-pentenedinitrile \\
\hline 7.404 & 2-methylenepentanedinitrile * & 7.404 & 2-methylenepentanedinitrile * & 7.935 & 2-methylenepentanedinitrile \\
\hline 7.651 & 2-methylpentanedinitrile & 7.651 & 2-methylpentanedinitrile & 8.054 & 2-methylpentanedinitrile \\
\hline 7.917 & 3-methylbenzonitrile & 7.917 & 3-methylbenzonitrile & - & - \\
\hline 8.529 & 3-chlorobenzonitrile & 8.529 & 3-chlorobenzonitrile & - & - \\
\hline- & - & 9.856 & Antimony compound & 10.057 & Antimony compound \\
\hline 10.551 & isophthalonitrile & 10.551 & isophthalonitrile & 11.090 & isophthalonitrile \\
\hline 13.935 & hexane-1,3,5-tricarbonitrile * & 13.935 & hexane-1,3,5-tricarbonitrile * & 14.456 & hexane-1,3,5-tricarbonitrile * \\
\hline 14.282 & pentane-1,3,5-tricarbonitrile & 14.282 & pentane-1,3,5-tricarbonitrile & 14.794 & pentane-1,3,5-tricarbonitrile \\
\hline 15.389 & hexane-1,3-5-tricarbonitrile & 15.389 & hexane-1,3-5-tricarbonitrile & 15.910 & hexane-1,3-5-tricarbonitrile \\
\hline
\end{tabular}

* Major peak

Figure 4 presents the SEM-EDX results of the char layers before/after the combustion of PANVDC films containing antimony oxide. As shown in Figure $4 \mathrm{a}, \mathrm{c}$, before the combustion of the ATO(3)- and ATO(4)-added films in PANVDC, antimony oxide was observed on the sample surfaces. After combustion, there was no ATO(3) in the PANVDC-ATO(3) char, and a smaller amount of ATO(4) remained in the PANVDC-ATO(4) char (Figure 4b,d). This is because $\mathrm{ATO}$ and $\mathrm{HCl}$ act mainly as flame retardants in the gas phase. In addition, $\mathrm{Sb}$ was detected on the surface of the PANVDC-ATO(4) because ATO(4) has a higher heat resistance after combustion.

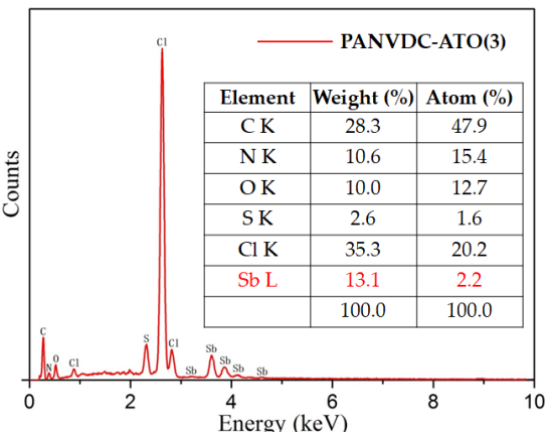

(a)

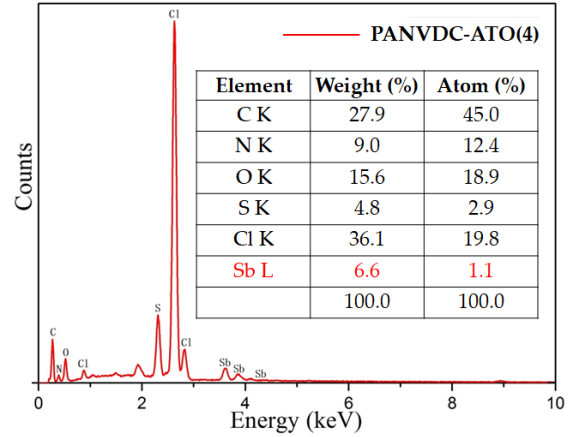

(c)

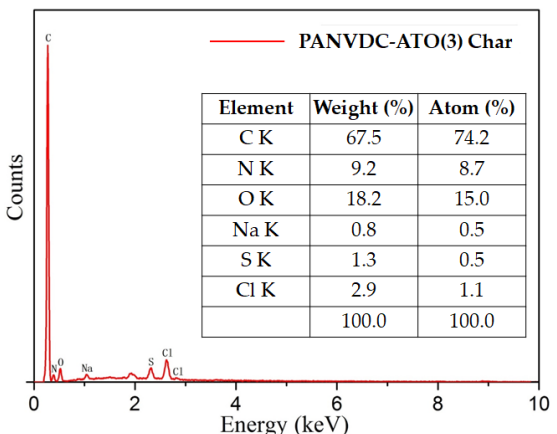

(b)

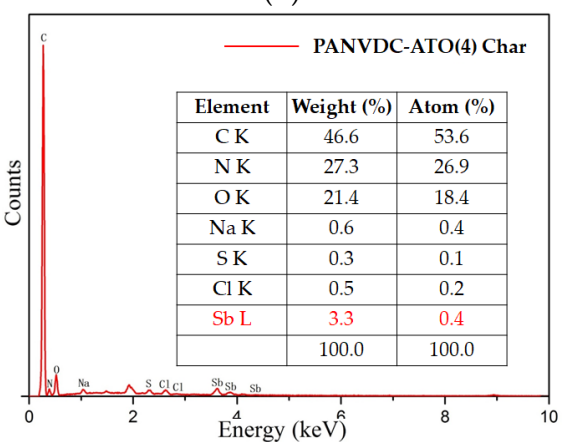

(d)

Figure 4. SEM-EDX analysis of the char layers before/after the combustion of PANVDC films containing antimony oxide; (a) before combustion of the ATO(3) film, after combustion of the (b) $\mathrm{ATO}(3)$ char, (c) ATO(4) film, and after combustion of the (d) ATO(4) char. 


\subsection{Flame Retardancy of PANVDC Films with Flame Retardants}

Table 2 lists the flame retardancy of PANVDC films with antimony oxides. This study was conducted using two methods: UL-94 and LOI of the vertical burning test to evaluate the relative flammability and the melt dripping of polymeric materials.

Table 2. Flame retardancy of the PANVDC films with antimony oxides.

\begin{tabular}{ccc}
\hline Sample & UL-94 & LOI (\%) \\
\hline Pure PANVDC & $-{ }^{\text {a }}$ & 26.4 \\
PANVDC-ATO(3) & V-0 & 29.0 \\
PANVDC-ATO(4) & V-0 & 31.2 \\
\hline
\end{tabular}

${ }^{a}$ Completely burned in the first burning.

Table 2 and Figure 5 present the UL 94 testing result and photographs of samples after the combustion process, which lasted $10 \mathrm{~s}$. Pure PANVDC was burned immediately when exposed to the flame, and extinguished itself when the flame was removed. As shown in Figure 5a, the PANVDC was totally burned and blackened by smoke during burning. On the other hand, when ATO(3) or ATO(4) were added to PANVDC films, approximately $30 \%$ of the sample was burned; hence, both samples presented a V-0 rating in the UL94 test. Thus, flame retardancy could be improved by adding antimony oxide to PANVDC.

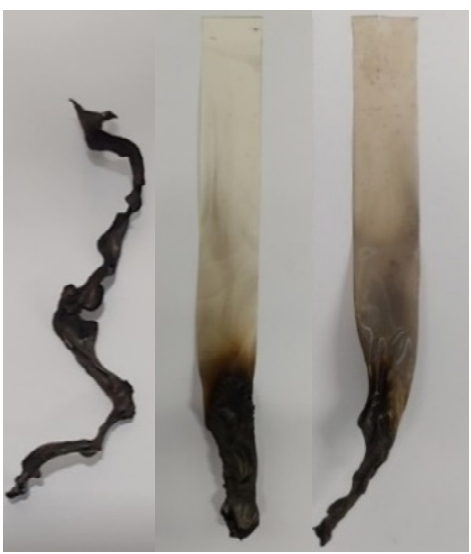

(a)

(b)

(c)

Figure 5. Images of the PANVDC Polymers after UL-94 tests: (a) Pure PANVDC; (b) PANVDCATO(3), (c) PANVDC-ATO(4).

Based on the above result, the LOI was measured to compare the relative flammability of both PANVDC-ATO(3) and PANVDC-ATO(4). As shown in Table 2, the LOI of pure PANVDC, PANVDC-ATO(3), and PANVDC-ATO(4) films were $26.4 \%, 29.0 \%$, and $31.2 \%$, respectively. The LOI values of the antimony oxide-added PANVDC were higher than pure PANVDC film. In addition, when comparing the types of antimony oxides, the LOI of PANVDC-ATO(4) was $31.2 \%$, higher than that of PANVDC-ATO(3), which was $29.0 \%$. This results indicate that $\mathrm{ATO}(4)$ exhibited higher flame retardancy efficiency because it has a high heat resistance owing to its stable structure and properties.

\subsection{Morphology and Mechanical Properties of the PANVDC Fibers with Flame Retardants}

Figure 6 shows the cross-sectional SEM images of the wet-spun fibers with ATO(3) and $\operatorname{ATO}(4)$. As shown in Figure 6, the PANVDC fiber and PANVDC fiber with the flame retardant had a round cross-section. In addition, no pores were observed in the PANVDC fiber, but several pores were presented in PANVDC-ATO(3) and PANVDCATO(4). Hence, pores generated as antimony oxide particles were added to pure PANVDC by interfering with solvent diffusion into/out of the fiber in the coagulation bath during wet spinning $[15,16]$. 


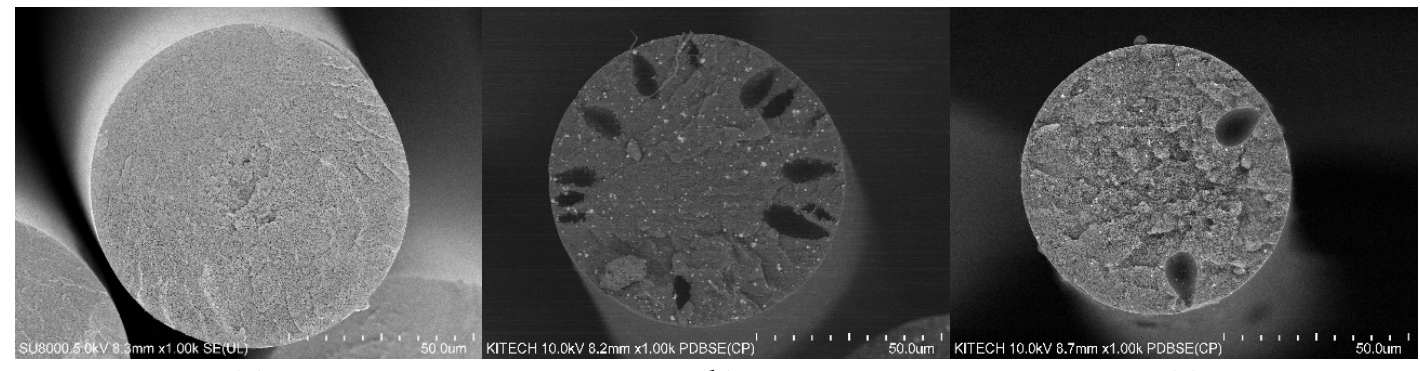

(a)

(b)

(c)

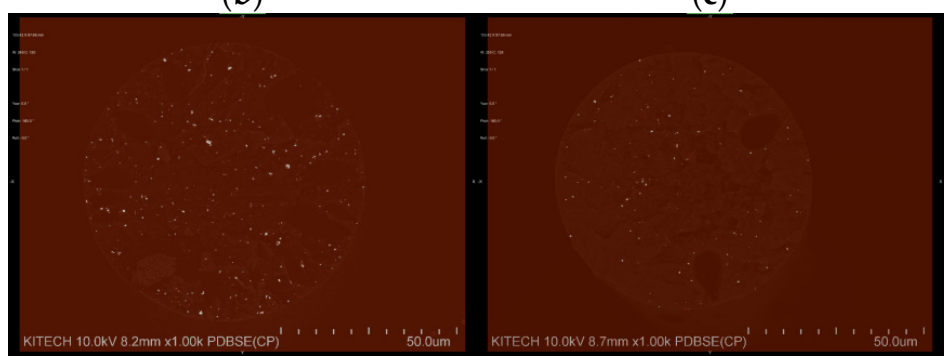

(d)

(e)

Figure 6. FE-SEM images of PANVDC fibers: (a) Pure PANVDC, (b) PANVDC-ATO(3), (c) PANVDC$\mathrm{ATO}(4)$ and images of distribution of (d)ATO(3) and (e) ATO(4) in PANVDC fiber.

Figure 7 shows the FE-SEM images of the ATO(3) and ATO(4) powder particles. As shown in Figure 7, the ATO(4) particles were smaller than the ATO(3) particles at the same magnification, which affected the formation of pores in the PAN fiber, and the number of pores of PANVDC-ATO(3) was greater than that of PANVDC-ATO(4). It is confirmed that the generation of pores increases as it acts as a factor preventing the solvent inside the fiber from spreading into the coagulation bath after spinning, since antimony trioxide has a relatively larger particle size than antimony tetroxide. In addition, as shown in Figure 6, the white dots observed in the SEM images of PANVDC-ATO(3) and PANVDC-ATO(4) are antimony oxide, showing that the flame retardant is introduced evenly at the cross-section of fibers. Therefore, the flame retardant barely eluted under the coagulation bath conditions during wet spinning and was well introduced into the fiber, ensuring flame retardancy.

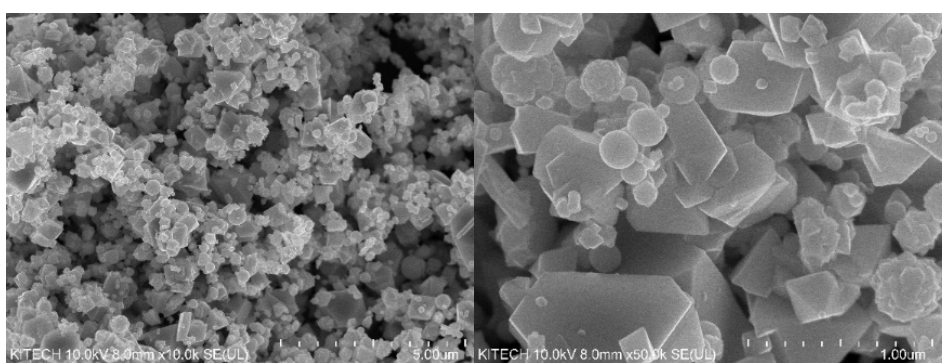

(a)

(b)

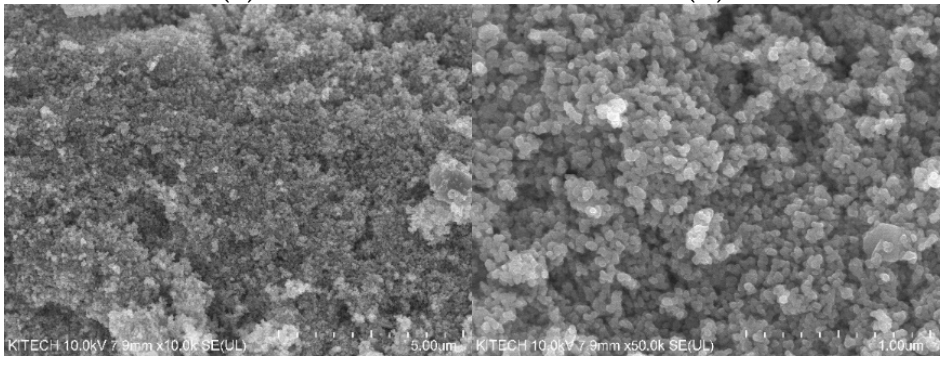

(c)

(d)

Figure 7. FE-SEM images of the powder particles of (a) ATO(3) $\times 10,000$, (b) $\mathrm{ATO}(3) \times 50,000$, (c) $\operatorname{ATO}(4) \times 10,000$, and (d) $\operatorname{ATO}(4) \times 50,000$. 
Table 3 and Figure 8 present the mechanical properties of PANVDC fibers with two types of antimony oxides. The three types of PANVDC fibers were washed and drawn in hot water baths in a continuous process to remove the excess solvent and increase the orientation of the PANVDC chains. As shown in Table 3, the tenacity values of the pure PANVDC, PANVDC-ATO(3), and PANVDC-ATO(4) were $4.42 \pm 0.25 \mathrm{~g} / \mathrm{den}$, $3.11 \pm 0.41 \mathrm{~g} /$ den, and $3.73 \pm 0.16 \mathrm{~g} /$ den, respectively. In the case of elongation, pure PANVDC, PANVDC-ATO(3), and PANVDC-ATO(4) showed an elongation of $12.52 \pm 0.34 \%$, $9.34 \pm 1.02 \%$, and $11.32 \pm 0.59 \%$, respectively. The PANVDC containing the flame retardants showed a slightly lower tenacity and elongation. As confirmed in the FE-SEM images, both tenacity and elongation decreased due to the effect of the pores formed by the addition of antimony oxide. The strength and elongation of PANVDC-ATO(4) were superior to those of PANVDC-ATO(3). The powder particle size of ATO(4) was relatively smaller than $\mathrm{ATO}(3)$, it was confirmed that relatively smaller particles were distributed in PANVDC-ATO(4) than in PANVDC-ATO(3), and there was a lower number of pores in the cross-sectional image of the fiber. Thus, PANVDC-ATO(4) exhibited superior mechanical properties compared to PANVDC-ATO(3).

Table 3. Mechanical properties of PANVDC fibers with antimony oxides.

\begin{tabular}{cccc}
\hline Sample & Tenacity (g/Den) & Fineness (Denier) & Elongation (\%) \\
\hline Pure PANVDC & $4.42 \pm 0.25$ & $5.39 \pm 0.44$ & $12.52 \pm 0.34$ \\
PANVDC-ATO(3) & $3.11 \pm 0.41$ & $5.31 \pm 0.45$ & $9.34 \pm 1.02$ \\
PANVDC-ATO(4) & $3.73 \pm 0.16$ & $4.29 \pm 0.20$ & $11.32 \pm 0.59$ \\
\hline
\end{tabular}

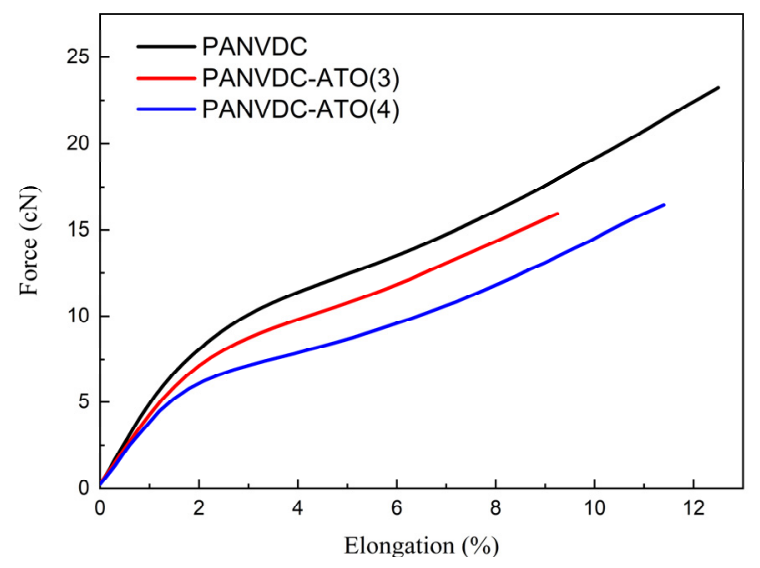

Figure 8. Average force/elongation curve of the drawn PANVDC fibers with the flame retardants.

\subsection{Thermal Properties of the PANVDC Fibers with the Flame Retardants}

Figure 9 and Table 4 present the TGA and derivative thermogravimetry (DTG) curves of the PANVDC fibers with antimony oxides. PANVDC showed the two main stages at around $250{ }^{\circ} \mathrm{C}$ and $580^{\circ} \mathrm{C}$ (Figure 9). 


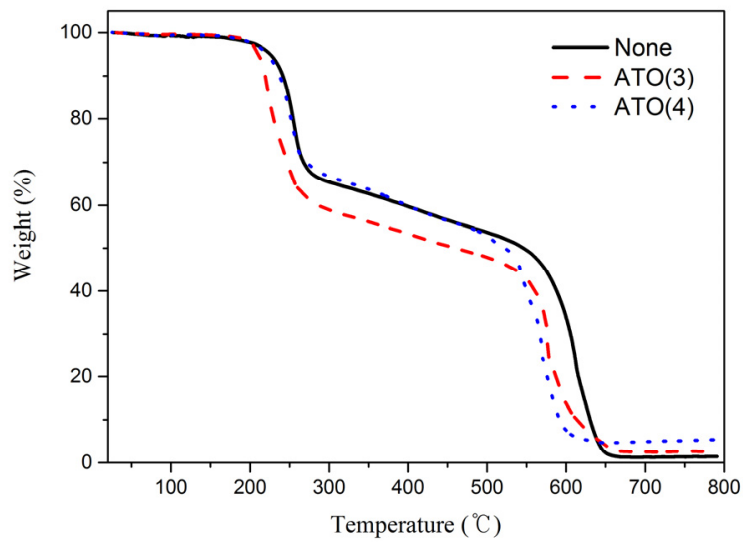

(a)

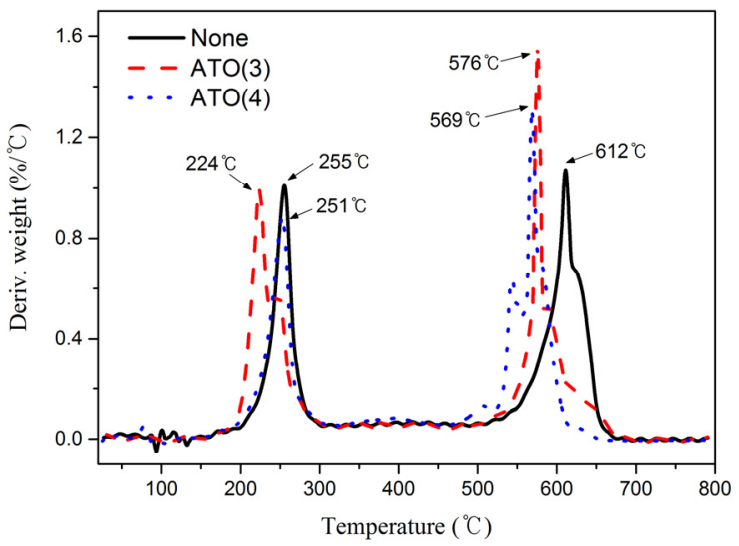

(b)

Figure 9. (a) TGA and (b) DTG curves of PANVDC fibers with antimony oxides at a heating rate $20{ }^{\circ} \mathrm{C} / \mathrm{min}$ to $800{ }^{\circ} \mathrm{C}$ under air conditions.

Table 4. TGA and DTG results of the PANVDC fibers with antimony oxides.

\begin{tabular}{ccccc}
\hline \multirow{2}{*}{ Sample } & \multicolumn{2}{c}{ First Stage } & \multicolumn{2}{c}{ Second Stage } \\
\cline { 2 - 5 } & TMR1 $^{*}\left({ }^{\circ} \mathbf{C}\right)$ & Mass Loss $(\%)$ & TMR2 * $\left({ }^{\circ} \mathbf{C}\right)$ & Mass Loss (\%) \\
\hline Pure PANVDC & 255 & 35 & 612 & 64 \\
PANVDC- & 224 & 41 & 576 & 56 \\
ATO(3) & 251 & 32 & 569 & 52 \\
PANVDC- & & &
\end{tabular}

* TMR1 and TMR2: Temperature at the maximum rate of mass loss $\left(\% /{ }^{\circ} \mathrm{C}\right)$ in the first and second stages, respectively.

The first stage was indicated to result from dehydrochlorination and the subsequent reactions generated by $\mathrm{HCl}$. The TMR1 of the PANVDC fibers with antimony trioxide was approximately $30^{\circ} \mathrm{C}$ lower than that of PANVDC. On the other hand, PANVDC fibers with antimony tetroxide showed a similar TMR1 to PANVDC $\left(255^{\circ} \mathrm{C}\right)$. At that time, the mass loss of PANVDC-ATO(3) was largest among the fibers, whereas that of PANVDC-ATO(4) was the smallest. Hence, the different properties of materials play an important role in the flame retardant effect of $\mathrm{ATO}(3)$ and $\mathrm{ATO}(4)$. Thus, $\mathrm{ATO}(4)$ has higher heat resistance properties than $\mathrm{ATO}(3)$.

The second-stage weight loss appeared to be caused by the decomposition of the char layer produced by the subsequent reaction after dehydrochlorination [16]. The TMR2 values of PANVDC, PANVDC-ATO(3), and PANVDC-ATO(4) were $612{ }^{\circ} \mathrm{C}, 576{ }^{\circ} \mathrm{C}$, and $569{ }^{\circ} \mathrm{C}$, respectively. The TMR2 was decreased when antimony oxide was added into 
PANVDC. This phenomenon is quite different from the first stage. On the other hand, the mass loss of PANVDC-ATO(4) (52\%) was lower than PANVDC (64\%) and PANVDC-ATO(3) (56\%). Only approximately $5 \%$ of the residue remained at $800{ }^{\circ} \mathrm{C}$ of PANVDC-ATO(4). As confirmed by SEM-EDX, heat resistance was improved because ATO(4), which has an excellent heat resistance and remains on the surface, unlike the other two samples that were completely burned.

\subsection{Migration of Antimony from PANVDC Fibers with the Flame Retardants}

The harmfulness of PANVDC fibers that contain antimony oxide flame retardants to the human body was assessed by conducting antimony dissolution tests in alkaline and acidic solutions at pH 8 and pH 1.2, respectively. The results are shown in Table 5.

Table 5. Migration of antimony oxide of PANVDC fibers with antimony oxides.

\begin{tabular}{ccc}
\hline \multirow{2}{*}{ Sample } & \multicolumn{2}{c}{ Sb Element (mg/kg) } \\
\cline { 2 - 3 } & \multicolumn{3}{c}{ Alkaline Solution (pH 8) } & Acidic Solutions (pH 1.2) \\
\hline PANVDC-ATO(3) & 60 & 114 \\
PANVDC-ATO(4) & 60 & 60 \\
\hline
\end{tabular}

In general, the antimony dissolution limit prescribed in each standard is $100 \mathrm{mg} / \mathrm{kg}$ in an alkaline solution and $60 \mathrm{mg} / \mathrm{kg}$ in an acidic solution. As a result of the antimony dissolution test, the amount of antimony elution from the PANVDC fibers introduced with $\mathrm{Sb}_{2} \mathrm{O}_{3}$ or $\mathrm{Sb}_{2} \mathrm{O}_{4}$ in an alkaline solution were all $60 \mathrm{mg} / \mathrm{kg}$, which was detected below the acceptable standard. In the acidic solution, however, PANVDC-ATO(3) and PANVDCATO(4) were $114 \mathrm{mg} / \mathrm{kg}$ and $60 \mathrm{mg} / \mathrm{kg}$, respectively. Hence, the PANVDC fibers containing $\mathrm{ATO}(3)$ had an elution amount over the reference value. Overall, $\mathrm{Sb}_{2} \mathrm{O}_{4}$ could replace $\mathrm{Sb}_{2} \mathrm{O}_{3}$ as a flame retardant in PANVDC fibers for high flame retardancy and safety.

\section{Conclusions}

This study aimed to find an alternative flame retardant to $\mathrm{ATO}(3)$. ATO(4) was selected because it has a higher thermal stability and acid and alkali resistance than ATO(3).

To confirm the possibility of the substitution of $\mathrm{ATO}(3)$, which is a representative flame retardant, ATO(4) was selected, and ATO(3)- or ATO(4)-added PANVDC film and wetspun fibers were fabricated. The flame retardancy was assessed by preparing a film. Both PANVDC-ATO(3) and PANVDC-ATO(4) passed the V-0 rating in UL-94. PANVDC-ATO(4) showed the highest LOI value of $31.2 \%$.

PANVDC fibers with antimony oxide were fabricated. The morphology, mechanical properties, and thermogravimetric analysis showed that the mechanical and thermal properties of PANVDC fibers with ATO(4) were superior to the PANVDC fiber with ATO(3). In addition, the migration of antimony analysis showed that the elution amount from PANVDC fibers with ATO(4) was below the acceptable standard.

Based on these results, ATO(4) can be used as an alternative flame retardant to ATO(3) in PANVDC fibers because of its high flame retardancy and safety in humans.

Author Contributions: Conceptualization, H.K., J.-S.K. and W.J.; investigation, H.K. and J.-S.K.; writing - original draft preparation, H.K.; writing—review and editing, H.K. and W.J.; supervision, W.J.; project administration, W.J.; funding acquisition, W.J. All authors have read and agreed to the published version of the manuscript.

Funding: This research was supported by the "Industrial Material Technology Development Project (10063549)" funded by the Ministry of trade, Industry, and Energy.

Institutional Review Board Statement: Not applicable.

Informed Consent Statement: Not applicable. 
Data Availability Statement: The data presented in this study are available in this article.

Conflicts of Interest: The authors declare no conflict of interest.

\section{References}

1. Tsai, J.-S. The effect of flame-redatardants on the properties of acrylic and modacrylic fibres. J. Mater. Sci. 1993, $28,1161-1167$. [CrossRef]

2. Bajaj, P. Fire-retardant materials. Bull. Mater. Sci. 1992, 15, 67-76. [CrossRef]

3. Bajaj, P.; Agrawal, A.K.; Dhand, A.; Kasturia, N.; Hansaraj. Flame retardation of acrylic fibers: An overview. J. Macromol. Sci. Part C Polym. Rev. 2000, 40, 309-337. [CrossRef]

4. König, S.; Kreis, P.; Herbert, C.; Wego, A.; Steinmann, M.; Wang, D.; Frank, E.; Bucheiser, M.R. Melt-spinning of an intrinsically flame-retardant polyacrylonitrile copolymer. Materials 2020, 13, 4826. [CrossRef] [PubMed]

5. Hall, M.E.; Zhang, J.; Richard, H.A. The flammability of polyacrylonitirile and its copolymers III. Effect of flame retardants. Fire Mater. 1994, 18, 231-241. [CrossRef]

6. Horrocks, A.; Kandola, B.K.; Davies, P.; Zhang, S.; Padbury, S. Developments in flame retardant textiles-A review. Polym. Degrad. Stab. 2005, 88, 3-12. [CrossRef]

7. Kim, Y.; Lee, S.; Yoon, H. Fire-safe polymer composites: Flame-retardant effect of nanofillers. Polymers 2021, 13, 540. [CrossRef] [PubMed]

8. Horrocks, A.R. The potential for bio-sustainable organobromine-containing flame retardant formulations for textile applicationsA review. Polymers 2020, 12, 2160. [CrossRef] [PubMed]

9. McPartlin, M.W.; Italiano, B.R.; Tiano, T.M.; Pilkenton, S.J.; Lawton, T.J. An approach to identifying fibers and evolved compounds from flame resistant fabrics. J. Anal. Appl. Pyrolysis 2021, 159, 105327. [CrossRef]

10. Riyazuddin; Bano, S.; Husain, F.M.; Khan, R.A.; Alsalme, A.; Siddique, J.A. Influence of antimony oxide on epoxy based intumescent flame retardation coating system. Polymers 2020, 12, 2721. [CrossRef] [PubMed]

11. Chin, H.S.; Cheong, K.Y.; Razak, K.A. Review on oxides of antimony nanoparticles: Synthesis, properties, and applications. J. Mater. Sci. 2010, 45, 5993-6008. [CrossRef]

12. Hazardous Substances Data Bank. Available online: https://www.nlm.nih.gov/toxnet/index.html (accessed on 27 September 2021).

13. Saerens, A.; Ghosh, M.; Verdonck, J.; Godderis, L. Risk of cancer for workers exposed to antimony compounds: A systematic review. Int. J. Environ. Public Health 2019, 16, 4474. [CrossRef]

14. Yildirim, S.; Celik, E. Production and characterization of the halogen-free and nanostructured flame retaradant reinforced composite coating. J. Aust. Ceram. Soc. 2020, 56, 68-695. [CrossRef]

15. Lee, S.H.; Yi, G.R.; Lim, D.Y.; Jeong, W.Y.; Youk, J.H. Study on the flame retardant and mechanical properties of wet-spun poly(acrylonitrile-co-vinylchloride) Fibers with antimony trioxide and zinc hydroxystannate. Fiber. Polym. 2019, $20,779-786$. [CrossRef]

16. Kim, J.S.; Song, J.E.; Lim, D.Y.; Ahn, H.; Jeong, W. Flame-retardant mechanism and mechanical properties of wet-spun poly(acrylonitrile-co-vinylidene choloride) fibers with antimony trioxide and zinc hydroxystannate. Polymers 2020, $12,2442$. [CrossRef] [PubMed]

17. Song, J.E.; Kim, J.S.; Lim, D.; Jeong, W. Preparation and characterization of zinc hydroxystannate coated by aluminum phosphate and its application in poly(acrylonitrile-co-vinylidene choloride). Polymers 2020, 12, 1365. [CrossRef] [PubMed]

18. Song, J.E.; Kim, J.S.; Lim, D.; Jeong, W. Zinc hydroxystannate coated by alumimum phosphate for improving its compatibility in falme-retardant poly(acrylonitrile-co-vinylidene choloride). Fiber. Polym. 2021, 22, 2156-2162. [CrossRef]

19. Surianarayanan, M.; Vijayaraghavan, R.; Raghavan, K.V. Spectroscopic investigations of polyacrylonitirile thermal degradation. J. Polym. Sci. Part A Polym. Chem. 1998, 36, 2503-2512. [CrossRef] 